\title{
3 Researchspurare \\ How Flushable Wet Wipes Are Causing Sewer Blockages - and An Approach to Prevent That
}

\author{
Thomas Harter \\ Graz University of Technology \\ Ingo Bernt \\ Kelheim Fibres \\ Stefanie Winkler \\ Kelheim Fibres \\ Ulrich Hirn ( $\nabla$ ulrich.hirn@tugraz.at) \\ CD Laboratory for Fiber Swelling and Paper Performance
}

\section{Research Article}

Keywords: Flushable, wet wipes, sewer blockage, dispersibility, nonwoven

Posted Date: February 2nd, 2021

DOl: https://doi.org/10.21203/rs.3.rs-154602/v1

License: (9) This work is licensed under a Creative Commons Attribution 4.0 International License. Read Full License

Version of Record: A version of this preprint was published at Scientific Reports on April 12th, 2021. See the published version at https://doi.org/10.1038/s41598-021-86971-z. 


\section{Abstract}

Scientific publications and newsfeeds recently focused on flushable wet wipes and their role in sewage system blockages. It is stated that although products are marked as flushable, they do not disintegrate after being disposed of via the toilet. In this work it is shown that wetlaid hydroentangled wet wipes lose their initially good dispersive properties during their storage in wet condition. This behaviour is found for both, wet wipes from industrial production and wipes produced on pilot facilities. It is demonstrated that the deterioration of the wipe's ability to disintegrate during wet storage is linked to the type of cellulosic fibres used. Only wipes made from a combination of band-shaped viscose fibres and unbleached softwood pulp fibres were preserving good disintegration during wet storage. The results are also suggesting to add tests after defined times of wet storage when assessing the flushability of wet wipes.

\section{Introduction}

Wet wipes, with their broad range of applications, are part of the modern life and can be found in many households in a form like it is depicted in Fig. 1 (left). Especially the demand on personal hygiene products has increased and is forecasted to rise by $8.0 \%$ p.a. in the next years (Mango, 2018). Convenience and hygiene require the easy disposal of these wipes, preferably right after use. This creates a market for biodegradable and flushable products. Both terms must be discussed separately as wipes that are marked flushable are not necessarily biodegradable. Therefore, the term "truly flushable" was introduced (Phillip Mango, 2004) for wipes that, after successfully being disposed via sewage, are also able to degrade in nature.

Biodegradability thereby is defined as a breakdown mechanism that creates simple substances in a biological way (Blackburn, 2005; Polman et al., 2021). In the list of fibres used in nonwovens (Mango, 2018) two groups of polymers, cellulose and PLA (polylactic acid), fulfil this criterion (Okada, 2002), where the biodegradability of PLA in a marine environment is in discussion recently (Narancic et al., 2018). Over $50 \%$ of the raw materials used in wet wipes are cellulosic natural biopolymers such as regenerated fibres (Rayon and Lyocell), wood pulp and cotton (Mango, 2018), that are all able to biodegrade in an aquatic environment (Zambrano et al., 2019). For a product to be fully biodegradable it must entirely consist of these materials, however synthetic fibres can be found in wet wipes labelled as flushable (Ó Briain et al., 2020; Pantoja Munoz et al., 2018). Toilet paper as an example is a material which solely consists of cellulosic pulp and disintegrates well after disposal (Eren and Karadagli, 2012). Wet wipes produced as a blend of viscose fibres and wood pulp show sufficient strength for proper usage of the wipe (Zhang et al., 2019a). They consist only of cellulosic material (Zhang et al., 2019a) and therefore are biodegradable (Soukupova et al., 2007). In these wipes the long viscose fibres form the loadcarrying structure providing wet strength, the pulp fibres attached to the body are responsible for liquid absorption and dispersive properties (Zhang et al., 2017). The production process of these wipes, a combination of wetlaid forming of the fabric and subsequent hydroentanglement with ,high-pressure water jets (Mao and Russell, 2006), requires no chemical agents as additives or binders. For disposal it has to be possible to flush the wet wipes down the sewage system. According to the guidelines of the 
nonwoven industry association of America (INDA) and Europe (EDANA) flushability is tested in a row of tests, where particularly the slosh box disintegration test is considered as suitable to determine the dispersibility of wipes (INDA and EDANA, 2018). As they are not containing any type of binders nonwovens from pure cellulosic fibres seem to be the most promising material to obtain true flushability, also according to slosh box tests (Atasagun and Bhat, 2018; Phillip Mango, 2004).

Flushability and labelling wet wipes as flushable have been in public discussion recently (Campbell, 2018; Hassan, 2019; Kary, 2019). One reason for this public interest could be the newsfeeds that reported major blockages in the New York (Flegenheimer, 2015) and London (Taylor, 2017) sewer system. Fatbergs, as these massive blockages are called in the media, consist of undispersed wet wipes and fatty deposits (Taylor, 2017), compare Fig. 1 (right). These deposits form in the sewer system from disposed fats, oils and greases (He et al., 2011; Kusum et al., 2020). Field measurements in Berlin (Mitchell et al., 2020; Thamsen et al., 2017) and Tokyo (Okamoto, 2018) as well suggest that blockages are caused by undispersed wet wipes disposed via the toilet (Thamsen et al., 2017). Next to wrongly disposed nonflushable wipes (Karadagli et al., 2021) these investigations also found so-called flushable wipes that did not disperse properly (Atasağun and Bhat, 2019; Joksimovic et al., 2020; Khan et al., 2019). In a broad study investigating flushability of consumer products all 23 tested fabrics, including wet wipes, labelled as flushable were in fact found to only dissolve partly in the tests (Joksimovic et al., 2020).

A lot of work has been done investigating the dispersive properties of wetlaid hydroentangled wipes (Deng et al., 2018; Karadagli et al., 2009; Tang and Jin, 2012; Zhang et al., 2019a, 2019b, 2018; Zhang and Jin, 2018). In all these studies the wipes dispersed well but were tested without prior wet storage, the dry webs were put in the dispersion test, which is also common practice in industrial testing. In the actual end use however, the wet wipes are stored wet in their packages for weeks and months before disposal. Recent publications (Atasağun and Bhat, 2019; Joksimovic et al., 2020) showed that different types of commercially available wet wipes show poor dispersible behaviour. With the comparison of the good dispersibility of dry tested nonwovens (Deng et al., 2018; Karadagli et al., 2009; Tang and Jin, 2012; Zhang et al., 2019b, 2018; Zhang and Jin, 2018) and the bad dispersibility of commercially available wet wipes (Atasağun and Bhat, 2019; Joksimovic et al., 2020) it stands to the reason, that wet storage of nonwovens has reduced the dispersibility of those wipes.

In this work we will show that dispersibility of flushable wet wipes, measured with the slosh box disintegration test, can decrease drastically over wet storage time. For this decrease in dispersibility of the wet wipes during wet storage, we coined the term 'ageing effect'. We will show that without wet storage the wipes are showing excellent dispersibility, however they are losing these properties within 24 hours of wet storage. This loss of dispersibility is demonstrated for wipes from industrial production as well as for wipes produced on pilot scale. We will also demonstrate that by selecting suitable fibres to produce the wet wipe, it is possible to obtain wipes with little to no ageing effect, thus proving that the widespread wetlaid/hydroentanglement process is suited to manufacture biodegradable and truly flushable wet wipes. Still, stable dispersibility over wet storage was only found for one set of fibres not currently used 
for commercial products as far as we know, indicating that typical commercially available wet wipes are deteriorating in their dispersibility properties during wet storage in the consumer package.

\section{Materials And Methods \\ 2.1. Raw Materials}

The fibres used for the wet wipes are a blend of viscose fibres with chemical pulp fibres. The viscose fibres were produced in an industrial scale viscose fibre line(Cook, 1984) at Kelheim Fibres (grade A and B). Viscose fibre $A$ is a flat viscose fibre with a rectangular cross section, a fibre length of $10 \mathrm{~mm}$ and a linear mass density (called titer in textile engineering) of 2.4 dtex ( $2.4 \mathrm{~g}$ per $10.000 \mathrm{~m}$ fibre). The second fibre (viscose fibre B) has a roundish, irregular-shaped cross section and a fibre length of $8 \mathrm{~mm}$, it is a finer fibre with a titer of $0.9 \mathrm{dtex}$. The fibres consist of cellulose and have a surface finishing with ethoxylated fatty acid according to viscose fibre industrial standards (Wilkes, 2001). The chemical pulps are a bleached softwood kraft pulp (SW-BK) and an unbleached softwood kraft pulp (SW-UBK), both commercially available grades from industrial production. The specifications of these pulps are listed in Table 1. The Kappa number, measured according to ISO 302:2004, is indicating the lignin content of the pulps, nearly all the lignin has been removed from the bleached pulp grade.

Table 1

Specifications of the used pulp grades

\begin{tabular}{|llll|}
\hline Type & $\begin{array}{l}\text { Length-weighted average fibre } \\
\text { length [mm] }\end{array}$ & $\begin{array}{l}\text { Kappa } \\
\text { number } \\
\text { ISO } \\
\mathbf{3 0 2 : 2 0 0 4}\end{array}$ & Wood type \\
\hline $\begin{array}{l}\text { SW- } \\
\text { BK }\end{array}$ & 2.368 & 0.5 & $\begin{array}{l}\text { North American Softwood (spruce, } \\
\text { pine, fir) }\end{array}$ \\
\hline $\begin{array}{l}\text { SW- } \\
\text { UBK }\end{array}$ & 2.453 & 10.1 & European SW (spruce, pine, larch) \\
\hline
\end{tabular}

All used materials are of cellulosic origin and therefore biodegradable. The blends of these viscose fibres with the bleached pulp are representing standard recipes for flushable wet wipes produced for consumer markets. The unbleached softwood kraft pulp was only used in the laboratory wipes and represents a prototype for possible future applications.

\subsection{Wet wipe production - Pilot scale}

The pilot-scale method has been adapted to mimic the industrial production process described below. The production of the tested wipes includes 4 steps. In a first step an inclined wire wetlaid former with a web width of $290 \mathrm{~mm}$ was used to form a fibre web where the fibres were primarily aligned in machine direction. Web speed is $4 \mathrm{~m} / \mathrm{min}$. Similar to paper production the nonwoven was dried with air at $160^{\circ} \mathrm{C}$ and a web draw of $0.1 \mathrm{~m} / \mathrm{min}$. These two steps provided a bulky and weak non-woven fabric. For the proper usage of these fabrics as personal care wet wipes hydroentanglement was used to create the 
required tensile strength. For this procedure the fabric was passing 3 bars of spray nozzles applying water jets to the fabric, created by pressures of 5,60 and 70 bars. The water jet nozzles were mounted at 40 holes per inch, each hole $0.1 \mathrm{~mm}$ in diameter. Web speed is $5 \mathrm{~m} / \mathrm{min}$. After hydroentanglement the web was dried on-line at $130^{\circ} \mathrm{C}$. A full list of the produced reel materials can be found in Table 2 . The targeted grammage of the nonwovens was $65 \mathrm{~g} / \mathrm{m}^{2}$.

Table 2 List of produced pilot-scale nonwovens. PW stands for pilot web, VA/VB for viscose type and BSK/UBSK for the pulp grade.

\begin{tabular}{|llll|}
\hline Name & Viscose fibre & Pulp & $\begin{array}{l}\text { Mass Ratio } \\
\text { Viscose/Pulp }\end{array}$ \\
\hline PW1 - VB BSK & Viscose fibre B & Bleached Softwood Kraft pulp & $20: 80$ \\
\hline PW2 - VA UBSK & Viscose fibre A & Unbleached Softwood kraft pulp & $20: 80$ \\
\hline PW3 - VA BSK & Viscose fibre A & Bleached Softwood Kraft pulp & $20: 80$ \\
\hline PW4 - VA BSK & Viscose fibre A & Bleached Softwood Kraft pulp & $30: 70$ \\
\hline PW5 - VB BSK & Viscose fibre B & Bleached Softwood Kraft pulp & $30: 70$ \\
\hline 2.3. Wet Wipe production & - InduStrial SCale & \\
\hline
\end{tabular}

In order to investigate the behaviour of the actual consumer product also an industrial production facility was used to produce non-woven fabrics. Therefore, one of worldwide largest producer for hydroentangled wetlaid nonwovens provided us with the nonwovens listed in Table 3 manufactured in a standard process for consumer wet wipes. Both components, viscose fibres and pulp, were the same products like in the pilot-scale produced fabrics, but from different production lots. The machinery to produce the fabrics was similar to the pilot-scale method but web forming and the hydroentanglement process are carried out inline. Therefore, these fabrics were only dried once, after the hydroentanglement.

Table 3

List of nonwovens from industrial production. IW stands for industrial web, VA/VB for viscose type and BSK for bleached softwood Kraft pulp.

\begin{tabular}{|llll|}
\hline Name & Viscose fibre & Pulp & $\begin{array}{l}\text { Mass Ratio } \\
\text { Viscose/Pulp }\end{array}$ \\
\hline IW1 - VA BSK & Viscose fibre A & Bleached Softwood Kraft pulp & $20: 80$ \\
\hline IW2 - VA BSK & Viscose fibre B & Bleached Softwood Kraft pulp & $20: 80$ \\
\hline IW3 - VA BSK & Viscose fibre A and B & Bleached Softwood Kraft pulp & $13: 7: 80$ \\
\hline
\end{tabular}

\subsection{Wet wipe preparation and storage}


For the dispersibility measurement single wipes, $125 \times 175 \mathrm{~mm}$, were cut from the reel fabric. The grammage for all wipes was $65 \mathrm{~g} / \mathrm{m}^{2}$, giving a single wipe the weight of $1.4 \mathrm{~g}$. Orientation effects were eliminated as the wipes were always cut in the same direction. For consumer products the wipes were stored in a lotion aimed to improve skin comfort and scent of the product. For storage we used both, deionized water and lotion. The liquid was applied to the cut wipes in a mass ratio of 2:1 (liquid : ambient condition dry mass of wet wipe) and stored in a closed plastic bag. For the measurements with the lotion the web PW1 - VB BSK was used. The lotion consists of $95.9 \mathrm{w} \%$ of water and chemicals, similar to a widely used patent (Marsh, 2016). Apart from water the lotion contains 1.5\% thickener (Propylenglycol), emulgators ( $0.8 \%$ castor oil and $0.45 \%$ silicone polyether), $0.5 \%$ buffer (citric acid) as well as stabilizers, other emulgators and preservation agents. To avoid bacterial and fungal decay the bags with the wet wipes were stored in a refrigerator at $4^{\circ} \mathrm{C}$. For each measurement point three wipes were stored in one plastic bag.

\subsection{Dispersibility measurement - Slosh box disintegration test}

Many methods exist to determine the dispersive behaviour of wet wipes (Karadagli et al., 2009; Zhang et al., 2019a, 2019b), in this work we used the slosh-box-test. As a testing method that is used by the nonwoven industry (INDA and EDANA, 2018) and the water service companies (IWSFG, 2018) the slosh box test is a widely accepted method to characterize the dispersibility of wet wipes. The test specifications used in this work were the same as provided by the INDA/EDANA guidelines (INDA and EDANA, 2018). As suggested by the International Water Services Flushability Group (IWSFG) (IWSFG, 2018), the organization representing the interests of water service providers, the time for dispersion in the slosh box was set to 30 minutes.

For the test a plastic container $(435 \times 335 \times 270 \mathrm{~mm})$ was filled with 2 litres of tap water. One wet wipe was placed on the water, as shown in Fig. 2a. An engine was tilting the box back and forth with $26 \mathrm{rpm}$ for 30 minutes. The maximum tilting angle in both directions is $14.5^{\circ}$ (Fig. 2b). The wet wipe was supposed to disintegrate due to the gentle agitation. Subsequently the state of disintegration was evaluated by collecting the larger non-disintegrated parts of the wipe on a $12.5 \mathrm{~mm}$ hole sieve. Therefore the $12.5 \mathrm{~mm}$ sieve was stacked on a $200 \mu \mathrm{m}$ sieve, Fig. 2c, and the suspension was poured within 20 seconds from a height of $100 \mathrm{~mm}$ above the upper sieve. The distance between the two sieves was 27 $\mathrm{mm}$. The fibre material withheld on the sieves was collected and dried at $105^{\circ} \mathrm{C}$ for 4 hours. Then the mass of the two material fractions from the coarse $\left(m_{12.5 \mathrm{~mm}}[\mathrm{~g}]\right)$ and fine $\left(m_{200 \mu m}[\mathrm{~g}]\right)$ sieve was determined. Dispersibility was calculated via Eq. 1, a higher dispersibility value indicates a better dispersive behaviour.

$$
\text { Dispersibility }=\frac{m_{200 \mu m}}{m_{200 \mu m}+m_{12.5 m m}}[\%]
$$


The used slosh box tester consisted of three liquid containers next to each other (Fig. 2a). Thus, for each measurement point three individual sheets were sloshed, one in each box. After storage the wet wipes were directly put into the slosh box. The wipes were not dried prior to slushing like for other tests (Atasağun and Bhat, 2019; Tipper, 2016), as this is not representing actual consumer usage.

\section{Research Hypotheses}

Wet wipes are facing the problem that they are contributing to sewer blockages which is documented publicly (Drinkwater and Moy, 2017; Hassan, 2019) and scientifically (Mitchell et al., 2020). This is possible as so-called flushable wet wipes do not disperse when being purchased by consumers (Atasağun and Bhat, 2019; Joksimovic et al., 2020) even though they are labelled as a flushable product. In contrast to these occurrences many publications (Deng et al., 2018; Karadagli et al., 2009; Tang and Jin, 2012; Zhang et al., 2019b, 2018; Zhang and Jin, 2018) found good dispersible properties for wet wipe materials directly after production prior to applying any liquid to the fabrics. Taking all the presented findings into account it stands to reason that the storage conditions impact the dispersibility of wet wipes leading to our first hypothesis:

1. Storage conditions and storage time are liable for wet wipes to deteriorate their initially good dispersibility.

Both the good dispersibility of never wetted nonwovens and the missing dispersibility of consumer-sold wet wipes, whether they are marked flushable or not, were carried out by different work groups using diverse materials. The findings in these publications were always the same therefore, we add two more statements to our working hypothesis:

2. The production process of the precursor material does only impact the level of dispersibility but not the time dependent behaviour.

3. The type of applied liquid is not influencing any time dependent change in dispersibility. All of these effects that occur in wet wipes can also be caused by deionized water.

4. We will furthermore show that choosing appropriate fibers as a raw material for the wet wipe production, namely band-shaped viscose fibres and unbleached softwood pulp fibres, the good dispersibility of the wipes can be preserved during shelf storage.

\section{Results And Discussion}

Commercial wet wipes are usually treated with lotions improving the customer experience in terms of pleasant smell and skin comfort. The first trial was aimed at comparing if there is a difference in dispersibility loss over time between wet wipes stored in lotion and wet wipes stored in water, as the lotions are consisting mostly of water (Marsh, 2016). Figure 3 represents the difference between a wipe stored in lotion and the same wipe stored in deionized water. Both liquids lead to a pronounced decrease in dispersibility over the wet storage time. It is interesting that water, the liquid used to disperse the wipes, 
is at the same time the substance causing the solidification of the wipes. While lotion is initially slowing the ageing, over longer storage time also the dispersibility for the wet wipes in lotion drops to very low values. This is in full agreement with our hypotheses stating that (1) the wet storage is liable for the deteriorated dispersibility and (3) that the liquid type is not relevant for this effect.

This solidification during the wet storage we call the ageing effect of dispersibility. According to the INDA/EDANA guideline for wet wipes a minimum dispersibility of $60 \%$ is required (INDA and EDANA, 2018). The area below the dashed line at $60 \%$ dispersibility in the Figs. 3 to 6 indicates insufficient disintegration after being flushed. After two weeks of storage the wet wipes investigated in Fig. 3 hardly disintegrate at all in the slosh box test, their dispersibility is below $10 \%$. This is only an effect of the wet storage, the initial dispersibility of the dry fabrics is well above $70 \%$.

The wet storage time in our tests is even lower than the time commercial wet wipes are stored in their package before being sold to the consumer. The results from Fig. 3 are explaining the poor disintegration of commercially available wet wipes observed in other work, even for grades labelled flushable(Atasağun and Bhat, 2019; Joksimovic et al., 2020), as flushability tests are normally performed on the dry wipes. A slosh box flushability test that better reflects the real situation thus should be performed with wet wipes after a defined wet storage time, or should even test commercially available wet wipes collected from retailers.

Figure 4 presents the results for the wet wipes produced on the pilot plant for different types of viscose fibres and wood pulps. Except for PW 2, all wet wipes show a similar decline in dispersibility over the wet storage time. Although there is an offset in the level of the curves the slope is similar. All of the tested wipes have better dispersibility in the beginning, with an ongoing loss of this property over the time. The ageing effect of the dispersible properties was here found for most variations of viscose fibres and wood pulps. This is in good accordance to findings in other publications (Atasağun and Bhat, 2019; Durukan and Karadagli, 2019; Joksimovic et al., 2020) where a large amount of wet wipes with different materials was tested and none are reaching satisfactory dispersibility. In our investigations, Fig. 4, only one viscosepulp combination (PW 2) was able to overcome the loss in dispersibility. It was the wipes produced from unbleached softwood kraft pulp and band-shaped viscose fibres, validating our fourth research hypothesis.

Figure 4 also demonstrates that the type of viscose fibre is playing a role for dispersibility. Utilizing the same pulp, viscose fibre A (PW1 - VB BSK), which has a flat cross section, provides better dispersibility than viscose fibre B (PW3 - VB BSK) with a circular cross section. This has also been observed earlier (Zhang et al., 2019b), there the improved dispersibility had been attributed to the better access of shear forces to the flat viscose fibres during disintegration.

Similar to the findings shown in Fig. 4 tests were carried out for wipes from industrial scale production, manufactured by a commercial producer of nonwovens for wet wipes. Figure 5 depicts the results for wipes using the same viscose fibres and a similar bleached pulp as in the pilot-scale trials. IW1 VA BSK for example represents a wipe with flat viscose fibres (Fibre A). Again, the wipes show good dispersibility 
when tested dry but they undergo a loss in dispersibility over the wet storage time. This demonstrates that the reduction of dispersibility during wet storage occurs for both, wipes produced at industrial scale as well as pilot scale. A direct comparison is shown in Fig. 6. Although there are differences in the starting level, both, industrial and pilot-scale production wet wipes, show a similar rate of decline in dispersibility which is supporting the second statement of our working hypothesis. Considering that there are differences in machinery and parameters between pilot- and industrial scale production it is reasonable to conclude that the loss in dispersibility is rooted in the fibres used, and not in the production process.

\section{Conclusions}

It has been shown consistently that storage of wet wipes in water or water-based lotion, as it is the case for commercial products, is severely reducing their ability to disintegrate properly after usage. After 24 hours, latest after 168 hours, the dispersive properties for most of the tested hydroentangled wetlaid wipes are strongly reduced. Dispersibility of wipes tested without wet storage, represented as 0-hour dispersibilities in Fig. 4 to Fig. 6, are in good accordance to recent publications (Zhang et al., 2019a, 2019b, 2018; Zhang and Jin, 2018), confirming that initially the wet wipes are disintegrating well. The problem clearly is the storage of the wipes in water or lotion. It is not very intuitive that storage of a wet wipe fabric in water (or a water-based liquid) reduces its ability to be dispersed in water, yet this is exactly what is happening. Possible mechanisms causing this ageing effect could be related to long term swelling processes (Fang et al., 2013; Jawaid et al., 2011; Tajvidi et al., 2006), which are common to cellulosic fibres, swelling mediated interdiffusion between the fibre surfaces or mechanical deformation of the softened fibre networks during wet storage.

The reason that this effect has not been described, is probably due to the fact that this behaviour is quite unexpected and thus has not been examined so far. Nevertheless, it has profound environmental implications. In the supply chain, the time between producing a wet wipe (i.e. putting it in wet storage in the consumer package) and the sale in stores is by far longer than 168 hours. Thus, an even more severe loss in dispersibility may take place for wet wipes in commercial end use. Monitoring dispersibility of wet wipes after shelf storage will help to reduce sewer blockage and ensure proper disintegration and faster biodegradability of the wipes.

As one key consequence of the work presented here, we are suggesting to adapt the standard testing procedures for wet wipe flushability in such a way that also the reduction of dispersibility over time due to the ageing effect is covered. Such a procedure needs to include the test of wipes e.g. after 2, 4 and 12 weeks of wet storage, in order to correctly reflect the end use of the commercial product.

The ageing effect has been observed equivalently for industrial- and pilot-scale production wet wipes, the decrease in dispersibility is similar. For pilot-scale produced wipes, we demonstrated that using a combination of unbleached softwood pulp and band shaped viscose fibers, wet wipes with good 
dispersibility properties over wet storage can be made, see Fig. 4 . This shows that using appropriate fibres, truly flushable and biodegradable wet wipes from purely lignocellulosic material can be produced.

\section{Declarations}

\section{Declaration of competing interests}

The authors declare that they have no conflict of interest.

\section{Funding}

The financial support by the Austrian Federal Ministry for Digital and Economic Affairs and the National Foundation for Research Technology and Development is gratefully acknowledged. We also thank our industrial partners Mondi, Kelheim Fibres, and SIG Combibloc for their financial support.

\section{References}

1. Atasagun, H., Bhat, G., 2018. Advancement in flushable wipes: Modern technologies and characterization. J. Ind. Text.

2. Atasağun, H.G., Bhat, G.S., 2019. Assessing the structural, mechanical and dispersible characteristics of flushable nonwovens. Text. Res. J. https://doi.org/10.1177/0040517519873055

3. Blackburn, R.S., 2005. Biodegradable and sustainable fibres. Taylor \& Francis US.

4. Campbell, E., 2018. No "flushable" wet wipes tested so far pass water industry tests [WWW Document]. BBC. URL https://www.bbc.com/news/uk-46188354 (accessed 5.23.19).

5. Cook, G.J., 1984. Handbook of textile fibres: man-made fibres. Elsevier.

6. Deng, C., Liu, W., Zhang, Y., Huang, C., Zhao, Y., Jin, X., 2018. Environmentally friendly and breathable wet-laid hydroentangled nonwovens for personal hygiene care with excellent water absorbency and flushability. R. Soc. open Sci. 5, 171486. https://doi.org/10.1098/rsos.171486

7. Drinkwater, A., Moy, F., 2017. Wipes in Sewer Blockage Study. 21st Century Drain. Program. 13.

8. Durukan, S., Karadagli, F., 2019. Physical characteristics, fiber compositions, and tensile properties of nonwoven wipes and toilet papers in relevance to what is flushable. Sci. Total Environ. 697, 134135. https://doi.org/10.1016/j.scitotenv.2019.134135

9. Eren, B., Karadagli, F., 2012. Physical Disintegration of Toilet Papers in Wastewater Systems: Experimental Analysis and Mathematical Modeling. Environ. Sci. Technol. 46, 2870-2876. https://doi.org/10.1021/es203589v

10. Fang, H., Zhang, Y., Deng, J., Rodrigue, D., 2013. Effect of fiber treatment on the water absorption and mechanical properties of hemp fiber/polyethylene composites. J. Appl. Polym. Sci. 127, 942-949. https://doi.org/10.1002/app.37871

11. Flegenheimer, M., 2015. Wet Wipes Box Says Flush. New York's Sewer System Says Don't. New York Times LXIII, 1849-1895. 
12. Hassan, J., 2019. Britain's latest 'fatberg', a mass of grease and wet wipes in a sewer, is longer than 6 double-decker buses [WWW Document]. Washington Post. URL

https://www.washingtonpost.com/world/2019/01/09/britains-latest-fatberg-mass-grease-wet-wipesis-longer-than-double-decker-buses/?utm_term=.1c37fa8d2316 (accessed 5.23.19).

13. He, X., lasmin, M., Dean, L.O., Lappi, S.E., Ducoste, J.J., De Los Reyes, F.L., 2011. Evidence for fat, oil, and grease (FOG) deposit formation mechanisms in sewer lines. Environ. Sci. Technol. 45, 43854391. https://doi.org/10.1021/es2001997

14. INDA, EDANA, 2018. Guidelines for Assessing the Flushability of Disposable Nonwoven Products A Process for Assessing the Compatibility of Disposable Nonwoven Products with Plumbing and Wastewater.

15. IWSFG, 2018. International Water Services Flushability Group Flushability Specifications [WWW Document]. URL https://www.iwsfg.org/iwsfg-flushability-specification/ (accessed 10.12.20).

16. Jawaid, M., Abdul Khalil, H.P.S., Noorunnisa Khanam, P., Abu Bakar, A., 2011. Hybrid Composites Made from Oil Palm Empty Fruit Bunches/Jute Fibres: Water Absorption, Thickness Swelling and Density Behaviours. J. Polym. Environ. 19, 106-109. https://doi.org/10.1007/s10924-010-0203-2

17. Joksimovic, D., Khan, A., Orr, B., 2020. Inappropriate disposal of 'flushable' consumer products reasons for concern. Water Sci. Technol. 81, 102-108. https://doi.org/10.2166/wst.2020.087

18. Karadagli, F., McAvoy, D.C., Rittmann, B.E., 2009. Development of a Mathematical Model for Physical Disintegration of Flushable Consumer Products in Wastewater Systems. Water Environ. Res. 81, 459-465. https://doi.org/10.2175/106143008X357101

19. Karadagli, F., Theofanidis, F., Eren, B., 2021. Consumers' evaluation of flushable products with respect to post-disposal effects in wastewater infrastructures. J. Clean. Prod. 278, 123680. https://doi.org/10.1016/j.jclepro.2020.123680

20. Kary, T., 2019. In Fatberg Fight, NYC Goes to War Against Flushable Wipes [WWW Document]. Bloomberg. URL In Fatberg Fight, NYC Goes to War Against Flushable Wipes (accessed 5.23.19).

21. Khan, A., Orr, B., Joksimovic, D., 2019. Defining "Flushability" for Sewer Use.

22. Kusum, S.A., Pour-Ghaz, M., Ducoste, J.J., 2020. Reducing fat, oil, and grease (FOG) deposits formation and adhesion on sewer collection system structures through the use of fly ash replaced cement-based materials. Water Res. 186, 116304. https://doi.org/10.1016/j.watres.2020.116304

23. Mango, P., 2018. The Future of Global Nonwoven Wipes Market Forecasts to 2023, in: 57th Dornbirn Global Fiber Congress.

24. Mao, N., Russell, S.J., 2006. A framework for determining the bonding intensity in hydroentangled nonwoven fabrics. Compos. Sci. Technol. 66, 80-91.

https://doi.org/10.1016/j.compscitech.2005.05.030

25. Marsh, R.G., 2016. Stable Lotion emulsion composition and wet wipes. 14/867,059.

26. Mitchell, R.L., Gunkel, M., Waschnewski, J., Thamsen, P.U., 2020. Nonwoven Wet Wipes Can Be Hazardous Substances in Wastewater Systems-Evidences from a Field Measurement Campaign in 
Berlin, Germany. Front. Water-Energy-Nexus-Nature-Based Solut. Adv. Technol. Best Pract. Environ. Sustain. 313-316.

27. Narancic, T., Verstichel, S., Reddy Chaganti, S., Morales-Gamez, L., Kenny, S.T., De Wilde, B., Babu Padamati, R., O'Connor, K.E., 2018. Biodegradable Plastic Blends Create New Possibilities for End-ofLife Management of Plastics but They Are Not a Panacea for Plastic Pollution. Environ. Sci. Technol. 52, 10441-10452. https://doi.org/10.1021/acs.est.8b02963

28. Ó Briain, O., Marques Mendes, A.R., McCarron, S., Healy, M.G., Morrison, L., 2020. The role of wet wipes and sanitary towels as a source of white microplastic fibres in the marine environment. Water Res. 182, 116021. https://doi.org/10.1016/j.watres.2020.116021

29. Okada, M., 2002. Chemical syntheses of biodegradable polymers. Prog. Polym. Sci. 27, 87-133. https://doi.org/10.1016/S0079-6700(01)00039-9

30. Okamoto, N., 2018. Case Study of Preventing Clogging of Pumps Caused by Nonwoven Wipes in Tokyo 1812-1818.

31. Pantoja Munoz, L., Gonzalez Baez, A., McKinney, D., Garelick, H., 2018. Characterisation of "flushable" and "non-flushable" commercial wet wipes using microRaman, FTIR spectroscopy and fluorescence microscopy: to flush or not to flush. Environ. Sci. Pollut. Res. 25, 20268-20279. https://doi.org/10.1007/s11356-018-2400-9

32. Phillip Mango, 2004. Flushable Wipes Past Present Future. Nonwovens Ind. 64-71.

33. Polman, E.M.N., Gruter, G.J.M., Parsons, J.R., Tietema, A., 2021. Comparison of the aerobic biodegradation of biopolymers and the corresponding bioplastics: A review. Sci. Total Environ. 753, 141953. https://doi.org/10.1016/j.scitotenv.2020.141953

34. Soukupova, V., Boguslavsky, L., Anandjiwala, R.D., 2007. Studies on the Properties of Biodegradable Wipes made by the Hydroentanglement Bonding Technique. Text. Res. J. 77, 301-311. https://doi.org/10.1177/0040517507078239

35. Tajvidi, M., Najafi, S.K., Moteei, N., 2006. Long-term water uptake behavior of natural fiber/polypropylene composites. J. Appl. Polym. Sci. 99, 2199-2203. https://doi.org/10.1002/app.21892

36. Tang, Y., Jin, X.Y., 2012. Study on Flushability Testing of Wood Pulp Composite Spunlaced Nonwovens. Adv. Mater. Res. 610-613, 490-493. https://doi.org/10.4028/www.scientific.net/amr.610-613.490

37. Taylor, M., 2017. Total monster': Fatberg blocks London sewage system. The Guradian.

38. Thamsen, P.U., Gunkel, M., Waschnewski, J., Mitchell, R.-L., 2017. Investigations into wastewater composition focusing on nonwoven wet wipes. Czas. Tech. 1, 125-135. https://doi.org/10.4467/2353737xct.17.010.6107

39. Tipper, M.J., 2016. Flushability of Nonwoven Wet Wipes. University of Leeds.

40. Wilkes, A.G., 2001. The viscose process, in: Woodings, C. (Ed.), Regenerated Cellulose Fibers. Woodhead Publishing Limited, pp. 37-61. 
41. Zambrano, M.C., Pawlak, J.J., Daystar, J., Ankeny, M., Cheng, J.J., Venditti, R.A., 2019. Microfibers generated from the laundering of cotton, rayon and polyester based fabrics and their aquatic biodegradation. Mar. Pollut. Bull. 142, 394-407. https://doi.org/10.1016/j.marpolbul.2019.02.062

42. Zhang, Y., Deng, C., Qu, B., Zhan, Q., Jin, X., 2017. A Study on Wet and Dry Tensile Properties of Wood pulp/Lyocell Wetlace Nonwovens. IOP Conf. Ser. Mater. Sci. Eng. 241. https://doi.org/10.1088/1757899X/241/1/012013

43. Zhang, Y., Deng, C., Wang, Y., Huang, C., Zhao, Y., Jin, X., 2019a. A new dispersible moist wipe from wetlaid/spunlace nonwoven: Development and characterization. J. Ind. Text. 48, 1136-1150. https://doi.org/10.1177/1528083718757524

44. Zhang, Y., Jin, X., 2018. The influence of pressure sum, fiber blend ratio, and basis weight on wet strength and dispersibility of wood pulp/Lyocell wetlaid/spunlace nonwovens. J. Wood Sci. 64, 256263. https://doi.org/10.1007/s10086-018-1699-7

45. Zhang, Y., Xu, Y., Zhao, Y., Huang, C., Jin, X., 2019b. Effects of short-cut fiber type and water-jet pressure sum on wet strength and dispersibility of wood pulp-based wetlaid/spunlace wipes. Eur. J. Wood Wood Prod. 77, 33-43. https://doi.org/10.1007/s00107-018-1369-x

46. Zhang, Y., Zhao, Y., Latifi, M., Wang, R., Jin, X., 2018. Investigation of the mechanical and dispersible properties of wood pulp/Danufil wetlaid nonwovens with/without hydroentanglement. J. Text. Inst. 109, 647-655. https://doi.org/10.1080/00405000.2017.1362747

\section{Figures}
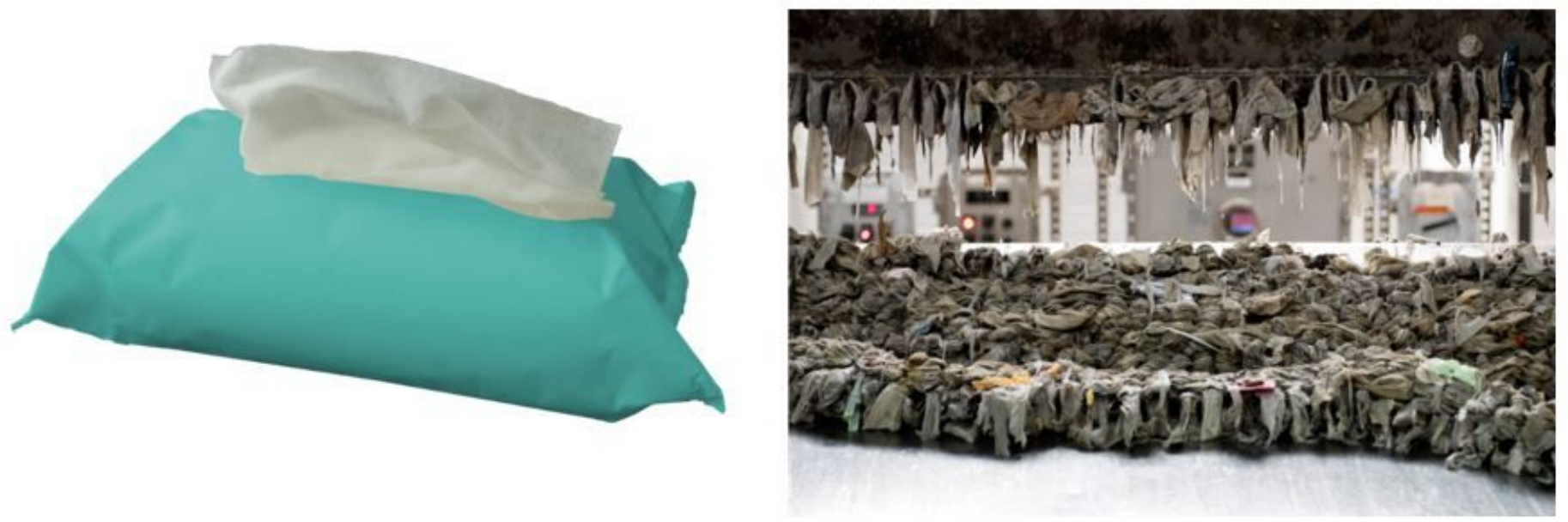

\section{Figure 1}

Wet wipe from industrial production after sheeting and packaging, similar to the wipes used in this work (left). Wipes removed from the New York city sewer system (right, Copyright New York Times, 2015). 
(a)

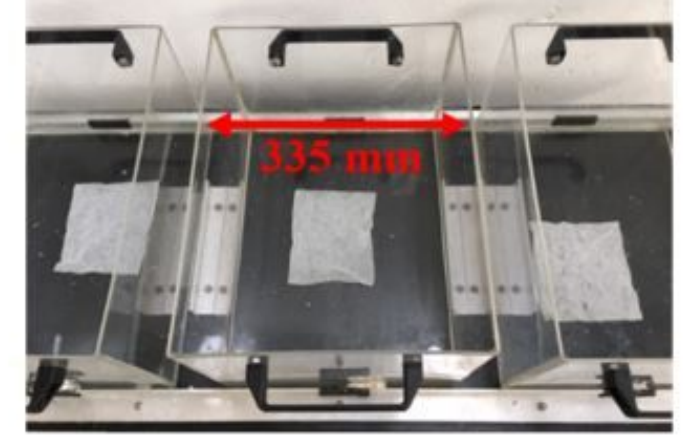

(b)

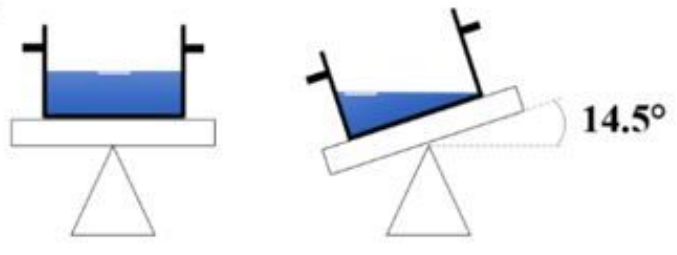

(c)
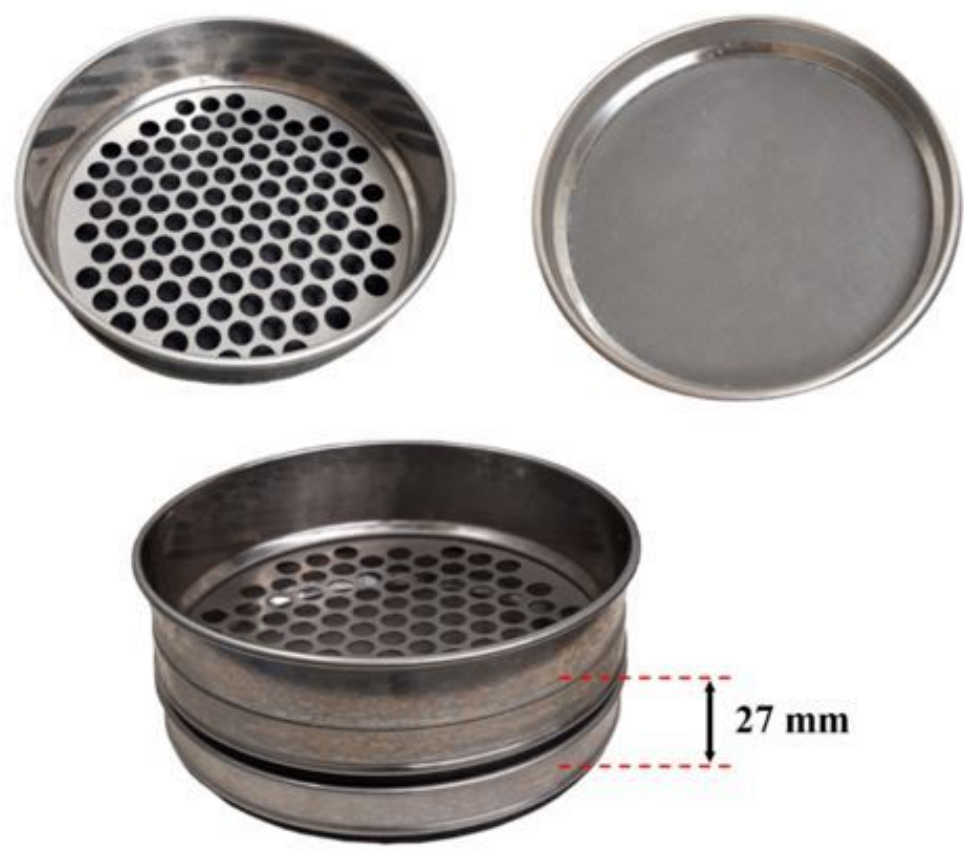

\section{Figure 2}

Slosh box principle: (a) top view of slosh box with a wipe $(125 \times 175 \mathrm{~mm})$, (b) scheme of slosh box side view with maximum tilting amplitude, (c) $12.5 \mathrm{~mm}$ hole sieve, $200 \mu \mathrm{m}$ mesh sieve and both sieves stacked on top of each other with a distance of $27 \mathrm{~mm}$. 


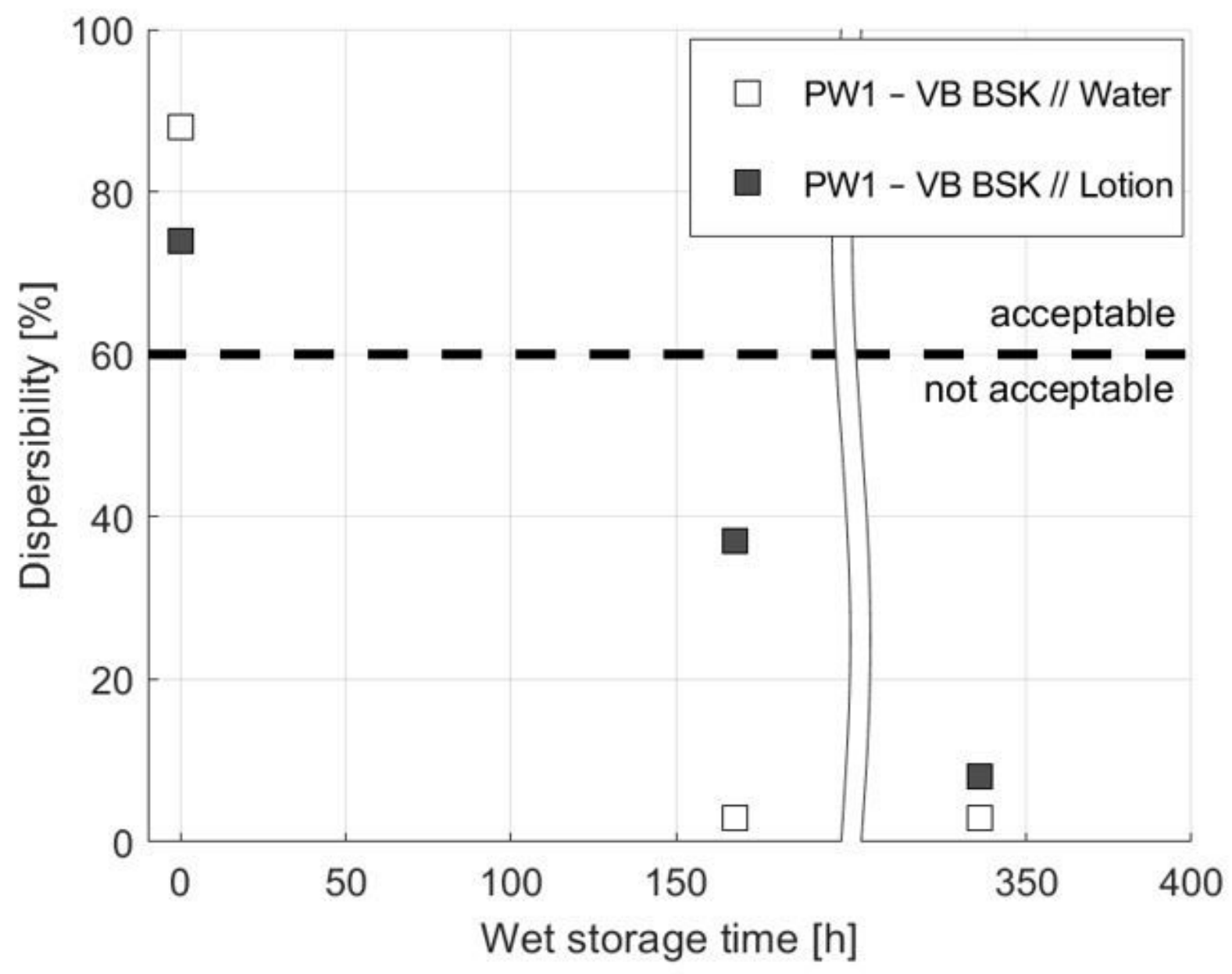

Figure 3

Reduction of wet wipe dispersibility due to wipe storage in water and wet-wipe lotion. Below a value of $60 \%$ dispersibility is insufficient according to INDA/EDANA(INDA and EDANA, 2018). 


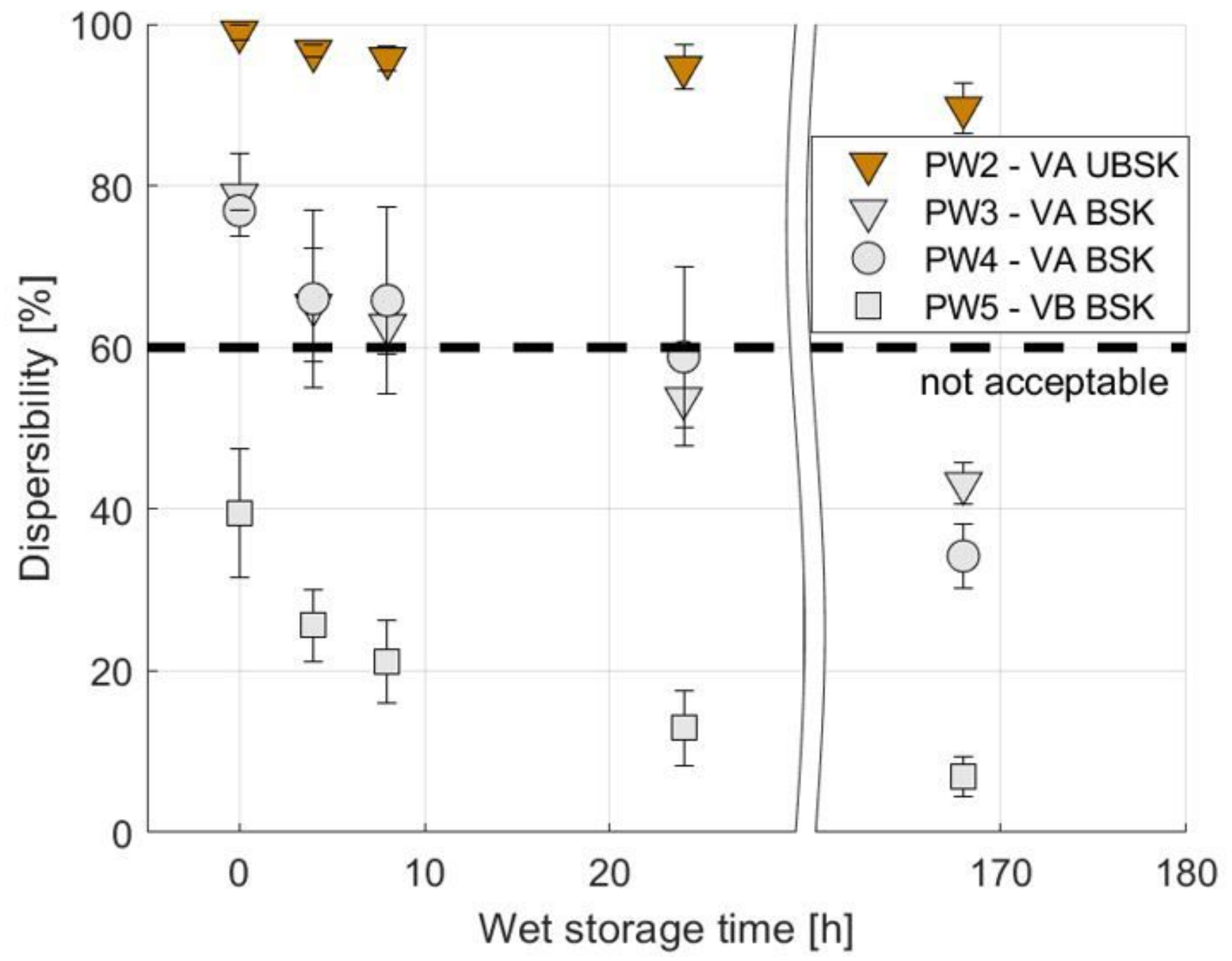

Figure 4

Reduction of wet wipe dispersibility due to storage in water for wipes produced from different raw materials (compare Table 2). Most wipes show a considerable decline in dispersibility, only the wipe produced with unbleached pulp (PW2 - VA UBSK) remains well dispersible over the entire storage time. Error bars represent one standard deviation. 


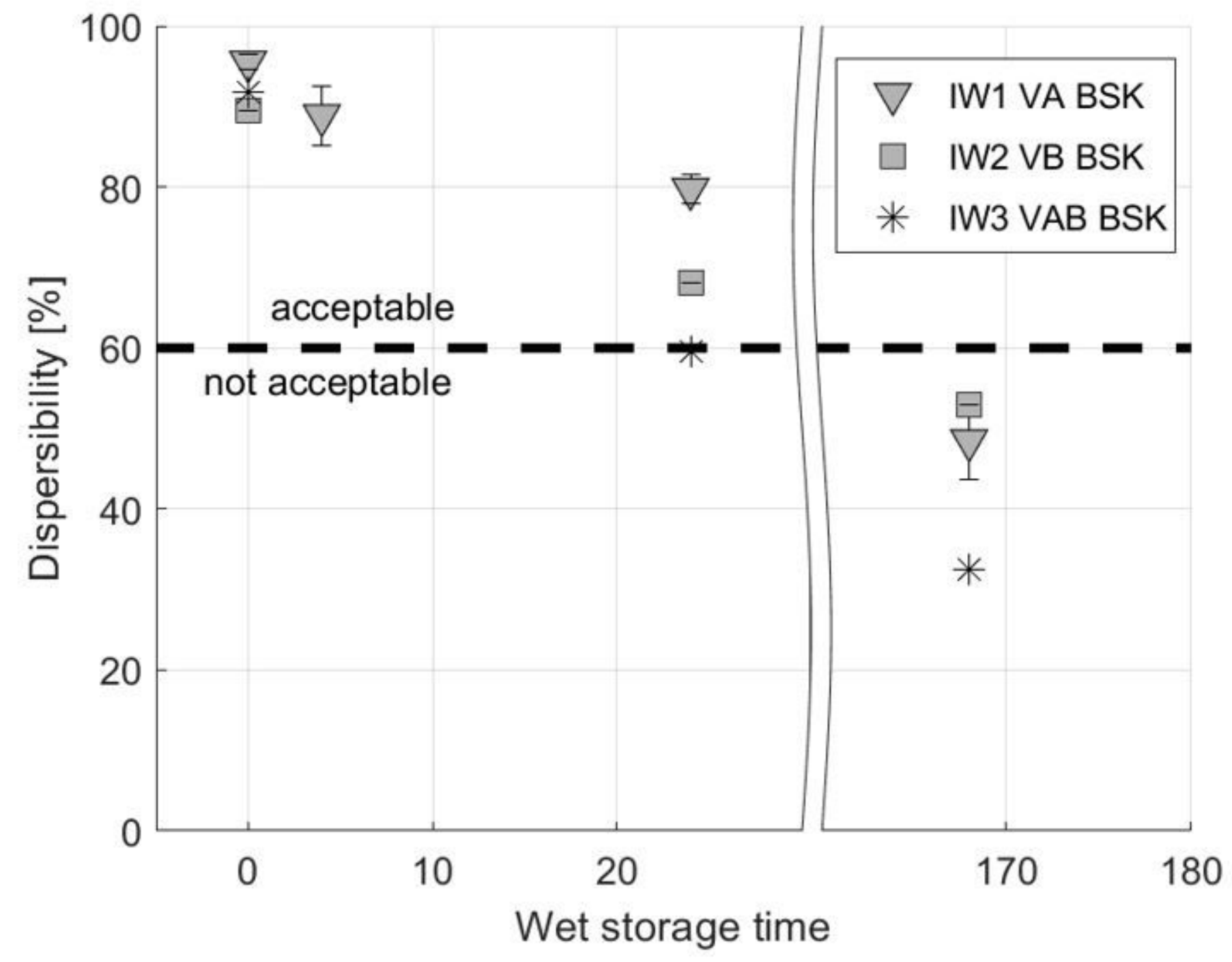

Figure 5

Reduction of wet wipe dispersibility due to storage in water for wipes from industrial production. All commercial products show a considerable decline in dispersibility over storage time. Error bars represent one standard deviation. 


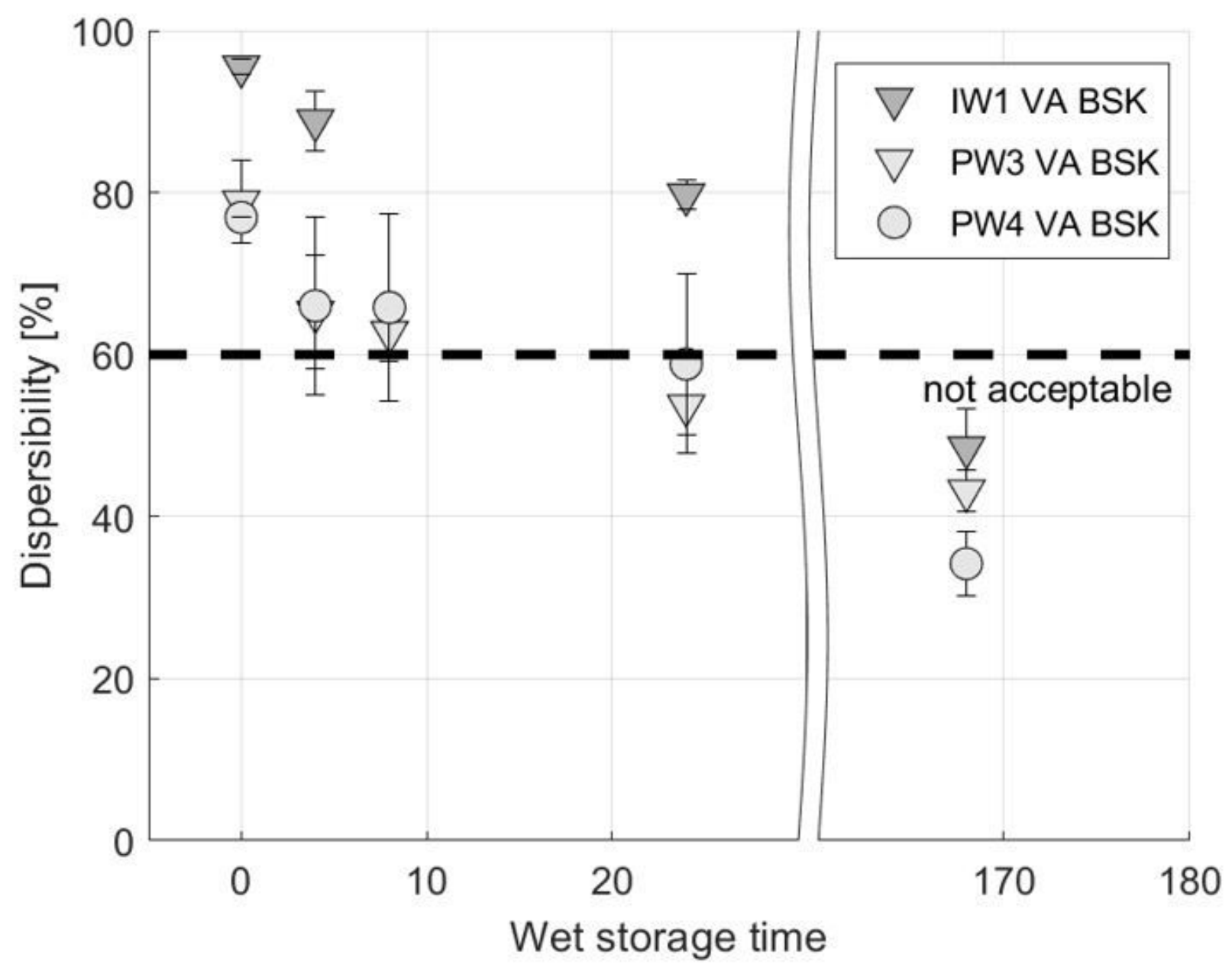

Figure 6

Wet wipe dispersibility after storage in water. Wipes were made in pilot production (PW3 VA BSK, PW4 VA BSK) and industrial production (IW1 VA BSK), using the same fibres. All products show the same ageing effect (deterioration in dispersibility). Error bars represent one standard deviation. 